\title{
ARTICLE
}

\section{Career-decision making of university students: cross-cultural comparisons between Mongolia and Japan}

Dulguun Damdin*, Toshiyuki Yamashita and Masami Ishihara

Graduate School of Humanities, Tokyo Metropolitan University, Tokyo, Japan

ARTICLE INFO: Received: 18 Sep, 2020; Accepted: 23 Aug, 2021

Abstract: The purpose of this study was to examine and compare Mongolians (118 men and 252 women) and Japanese (158 men and 201 women) university students' awareness related to their occupation and their motivations for entering university. The survey focused on the vocational motives, university performancelexperiences, and motivations for entering university. The analyses showed that although Mongolian and Japanese students have similar occupational views, there are some cultural differences that can be mainly identified with the recent historic developments and social changes both the nations experienced (e.g socialistic era in Mongolia).

Keywords: Career decision-making; Cross-cultural comparison; Mongolian social; Social changes in Developing Country; Mongolian students; Japanese students;

\section{INTRODUCTION}

The present study was conducted to clarify the differences and similarities between Japanese and Mongolians regarding their motivation to go to the university, life goals, experiences of being university students, and vocational awareness from the viewpoint of youth. When comparing youth of the two countries, we agreed that it is necessary to consider the historical background of Mongolia.

\section{Historical background of Mongolia}

Mongolia, whose ancestor was Genghis (Chinggis) Khan, who once controlled the largest land mass in human history, was under pressure from two neighboring countries China and Russia (former Soviet Union), until it became declared its independence and became a People's Republic in 1924 and subsequently, a satellite state of the Soviet Union until democratization in 1990.

During the socialist era, Mongolian traditional cultural personalities and intellectuals, and Buddhist monks were persecuted by the communist regime, which then was building a socialist system in Mongolia. The communist purges of the 1930s were an aggressive campaign to eliminate and punish the so-called 'counter-revolutionaries'. During the campaign, intellectuals were arrested and were summarily put on trial, then sent to the labor camps in Sibera or shot.

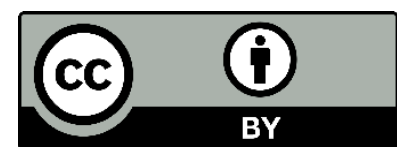

The Author(s). 2021 Open access This article is distributed under the terms of the Creative Commons Attribution 4.0 International License (https://creativecommons.org/licenses/by/4.0/), which permits unrestricted use, distribution, and reproduction in any medium, provided you give appropriate credit to the original author(s) and the source, provide a link to the Creative Commons license, and indicate if changes were made. 
The traditional vertical characters of the Uyghur Mongolian script were replaced with the horizontal Russian Cyrillic script. The Mongolians also replaced traditional nomadism with agricultural collectives called "Negdel", and people in the city started working at factories under Soviet Union's supervision. These systems completely denied the nomadic culture, the Mongolian identity, and consequently, their impacts are immeasurable [3].

Following the Soviet Union's collapse, Mongolia saw its own relatively peaceful democratic revolution in the early 1990 s, which led to a multi-party system, promulgation of a new democratic constitution in 1992, and transition to a free market economy. This transition resulted in an upheaval of structures that had been in place for 70 years and saw Mongolia's trade with Russia decline by 80 per cent, which had a most pernicious impact on peoples' lives. The fallout from the upheaval was serious, Soviet Union's financial support was lost, supplies declined, factories closed one after another, people who lost their jobs took to heavy drinking, and the gap between the rich and poor became widespread. Immediately after democratization, Mongolia started to build a nation from scratch in various fields such as the economy, education, and industry with the support of international organizations and donor countries.

\section{The current state of Mongolia}

At present, Mongolia's population is about 3.2 million, and the population composition is about 60 per cent under 30 years old [6], which shows that Mongolia is a relatively young country. The image of nomads in the country has changed drastically as the Mongolian herders are losing their pasture land to mining of mineral resources, such as, coal, molybdenum, copper, and uranium. Due to the rapid urbanization of Ulaanbaatar city in recent years, the nomads who lost their livelihoods due to mining and natural disasters, have been migrating to the city year to year seeking employment and education possibilities.

Before the collapse of the socialist system, in 1989 there were 8 universities and 46 technical vocational schools, and back then only 1.7 per cent of the population of Mongolia were obtaining higher education $[1,2,3]$. After the democratic transition, the number of universities increased to 200 in the last 25 years. As per percentage of the population, the education system of Mongolia is one of the fastest-growing in the world. Over last 25 years, Mongolia has been approaching a high level of development of Japan's 75 years after World War II. However, educational inequality has also arisen due to this situation [2]. As the population concentration grows in the cities and digitalization accelerates, the consciousness of the people has undergone enormous changes, 20 years ago one would not have imagined the Mongolians would be so strongly influenced by foreign cultures, as it happened in recent years. For example, nomads living in the grasslands now ride Japanese cars and use Western-made smart phones. Today, it has become possible to obtain information from all around the world, even in remote rural areas without difficulty due to widespread digitalization, such as the internet and satellite TV. The crisis after democratization caused a big struggle in education sector, but the recent Mongolian society and the educational outlook are gradually improving [3].

The aim of this study

Digitization is changing the nomads' consciousness, including that of the young generation. The impact of social changes can also be found in Japan, their awareness about career decisions, particularly after Japan's economic bubble burst in the early 1990s [7]. Coupled with the experience gained during the socialist era when freedom of choice of occupation was limited, Mongolians now have extensive opportunities for both economic and mental growth, thanks to the sweeping changes brought bout by the democratic changes and the rapid economic growth, partly thanks to foreign capital investment. The present study was designed to clarify the characteristics of Mongolia students' awareness regarding their career decision-making, which was juxtaposed with that of Japanese students and we discussed the differences and the similarities in the vocational attitudes and motives of youth of two countries. 


\section{MATERIALS AND METHODS}

The survey was conducted in September 2011 among students attending major universities (located in the metropolitan areas) in Mongolia and Japan. The survey was based on a questionnaire and performed a comparative analysis of Japan and Mongolia. For the survey conducted in Mongolia, we used a questionnaire translated from Japanese into Mongolian.

Participants

The participants were university students, aged 18 to 24, and 370 of them were Mongolians and 359 Japanese. The details of sample sizes by education are summarized in Table 1.

Table 1. Mongolian and Japanese Participants

\begin{tabular}{lrrrrrr}
\hline \multirow{2}{*}{ School Year } & \multicolumn{3}{c}{ Mongolian } & & \multicolumn{3}{c}{ Japanese } \\
\cline { 5 - 7 } \cline { 5 - 7 } & Men & Women & Total & Men & Women & Total \\
\hline Freshmen & 22 & 58 & 80 & 47 & 61 & 108 \\
Sophomores & 42 & 55 & 97 & 50 & 62 & 112 \\
Juniors & 32 & 122 & 154 & 15 & 54 & 69 \\
Seniors & 22 & 17 & 39 & 46 & 24 & 70 \\
Total & 118 & 252 & 370 & 158 & 201 & 359 \\
\hline
\end{tabular}

\section{Procedure}

Participants were instructed to attend the part of the lesson and then answer the questionnaire by selecting the answer number that fits their feelings without overthinking.

Questionnaire

A booklet of the questionnaire was given to each participant. The first page of the booklet contained instructions and blank spaces where the participant were to write their name, the name of the university, school year, gender, and age. The questionnaire contained six questions (including sub-questions); however, since questions \#4, 5, and 6 were not directly concerned with occupational decision-making, they were not considered in this article. The details of the questions described below are posted: We asked to rate on a 5-point scale anchored by 1: unimportant, and 5: very important, with 3: being neutral.

Question 1

Question 1 asked the participants to rate the 14 motives for studying at university. These items were based on Fuchigami's [8] five subscales.

"Original function of the university": Desire to deepen specialized knowledge, acquire specialized skills, widely acquire education, seek for one's potential, etc.
"Family consideration and normative function": Reasons for filial piety, parents' recommendation, teachers' advice.

"Moratorium function": People around me go on to school or do not want to be in society yet or want to spend time at university.

"A Secondary function of the university": Desire to get to know many people at university, take part in club activities at university, find a boyfriend (girlfriend), go to the city, etc.

"University's economic value function": the desire to find a job in a first-class company, live a wealthy life, etc.

Question 2

Question 2 asked the participants about their experiences at university and their consciousness toward employment. Question 2 consists of 13 items based on Yamashita et al. $[9,10]$.

Question 3

Question 3 asked the participants to rate 10 items of vocational motives on a 5-point scale. The items in our survey were based on reports by the Japan Institute of Labour [11, 12] and Yamashita et al. [9, 10]. Motives for a choice of career consisted of the following three subscales as "Emphasis on less-stress and wellregulated life," "Emphasis on income and social evaluation," and "Emphasis on motivation and ability." 


\section{RESULTS AND DISCUSSION}

\section{Vocational Motives}

Table 2 shows the mean ratings of the ten vocational motives obtained from Question 3 for both Mongolian and Japanese students.

The average rating values of vocational motives emphasized in both countries were "worth doing," "can demonstrate one's full ability," "very well paid," and "future stability." Among them, the Japanese students tended to attach importance to "worth doing" and "can demonstrate one's full ability" for both men and women. The Mongolian students tended to attach particular importance to "very well paid" and "future stability" for both men and women.

The obtained data were fed into a twoway analyses of variance (ANOVA) with country $(2) \times$ gender $(2)$ in order to investigate whether there is a difference between the two countries and/or gender and /or interaction.

As a result of ANOVA for the "future stability" item, the main effects of both country and gender were significant $[\mathrm{F}(1,723)=$ $183.24, \mathrm{p}=.000 ; \mathrm{F}(1,723)=14.33, \mathrm{p}=.000$, respectively]. This implies that the Mongolian students had a higher priority on "future stability" than their Japanese counterparts, and the women in both countries tended to emphasize "future stability" more than the men.

With regard to "highly appreciated by others and society", the main effects of both countries and gender were significant $[\mathrm{F}(1$, $723)=95.72, \mathrm{p}=.000 ; \mathrm{F}(1,723)=9.01, \mathrm{p}=$ .003 , respectively]. That is, Mongolian students attached higher priority to "highly appreciated by others and society" than the Japanese. Moreover, women students tended to emphasize social evaluation more than the men students.

In the "well-regulated life," the main effects of both countries and gender were significant $[\mathrm{F}(1,723)=35.65, \mathrm{p}=.000 ; \mathrm{F}(1$, $723)=5.48, p=.019$, respectively]. This implies that Mongolian students attached greater significance to regular lives than the Japanese, and that women tended to place more importance on it than men. Significant gender difference may be because of the role of women in household. Especially in families with small children, it is obvious that the time is fixed for daily life, such as picking up children from kindergarten and schools.

With regard to "not far from the place where now living", the main effects of both countries and gender, and country $\times$ gender interaction were significant $[\mathrm{F}(1,723)=49.48$, $\mathrm{p}=.000 ; \mathrm{F}(1,723)=7.66, \mathrm{p}=.006 ; \mathrm{F}(1,723)$ $=6.19, \mathrm{p}=.013$, respectively]. Since the interaction was significant, a simple main effect test was then performed, which showed that there were significant differences between countries for both men and women $[\mathrm{F}(1,723)$ $=36.52, p=.000 ; \mathrm{F}(1,723)=13.62, \mathrm{p}=.000$, respectively]. There was gender difference only in Japan $[\mathrm{F}(1,723)=14.48, \mathrm{p}=.000]$. These results suggest that Japanese people may not attach greater importance to commuting distance than the Mongolians and that Japanese men may not care about commuting distance than women. The results may be related to the fact that, compared to Japan, Mongolia does not have a subway, and public transport has been operated by buses and trolleybuses since the Soviet era. There are significant differences in the social development phase. Mongolia's land is vast and Mongolians' sense of distance differ from that of the Japanese.

\section{Performance and Experiences}

Table 3 shows the averages and standard deviations of the participants' responses obtained from the questionnaire regarding the university students' goals and experiences, revealing that the experiences of being students in the university life are important for them to make the next move and in job selection.

First of all, in the average rating value, both the countries showed high importance for the three items of "getting information about finding employment for oneself," "the importance of information processing skills," and "the importance of foreign language." It can be assumed that this is a skill that every modern person must acquire when people are living in a globalized world and in the information age. Next, we examined in detail the following four 
items for which the interaction was significant as a result of the ANOVA with country $(2) \times$ gender (2).

Regarding the item of "going on to graduate school" ANOVA showed that the main effect of the country, and the interaction were also significant $[\mathrm{F}(1,723)=329.86, \mathrm{p}=$ $.000 ; \mathrm{F}(1,723)=4.23, \mathrm{p}=.040$, respectively]. The simple main effect test revealed that there were significant differences between the countries in both men and women $[\mathrm{F}(1,723)=$ $104.45, \mathrm{p}=.000 ; \mathrm{F}(1,723)=269.52, \mathrm{p}=.000$, respectively]. There was a gender difference only in Japan $[F(1,723)=6.17, p=.013]$. These results suggest that while many Mongolians want to go to graduate school, the Japanese do not want to go to graduate school so much, especially women in Japan.
With regard to "getting information about finding employment for oneself", only the interaction of country $\times$ gender was significant $[\mathrm{F}(1,722)=11.04, \mathrm{p}=.000]$. The simple main effect test showed the differences between the countries in both men and women $[\mathrm{F}(1,722)=$ $5.56, \mathrm{p}=.019 ; \mathrm{F}(1,722)=5.66, \mathrm{p}=.018$, respectively]. Gender differences were found only in Mongolia $[\mathrm{F}(1,722)=9.98, \mathrm{p}=.002]$. These results suggest that Japanese women and Mongolian men may be passive, and Japanese men and Mongolian women may be positive. One possible explanation for this is that Mongolia's university entrance rate is 61.9 per cent [13], and the women to men ratio in tertiary education is $1: 41$, with many women receiving higher education $[13,2]$. Also, there is a trend that women, even during the socialist system, had been taking an active part in the society.

Table 2. MEAN Ratings of Vocational Motives (Question 3) For Mongolian and Japanese Students

\begin{tabular}{|c|c|c|c|c|c|c|c|c|c|}
\hline \multirow{2}{*}{ Motive } & \multicolumn{2}{|c|}{ Men } & \multicolumn{2}{|c|}{ Women } & \multicolumn{2}{|c|}{ Total } & \multicolumn{3}{|c|}{$\mathrm{ANOVA}+$} \\
\hline & $\mathrm{M}$ & $\mathrm{SD}$ & $\mathrm{M}$ & SD & $\mathrm{M}$ & $\mathrm{SD}$ & $\mathrm{C}$ & $\mathrm{G}$ & $\mathrm{C} \times \mathrm{G}$ \\
\hline 1. Short working hours per & day & & & & & & & $*$ & \\
\hline Mongolian & 3.14 & 1.30 & 2.85 & 1.38 & 3.00 & 1.34 & & & \\
\hline Japanese & 2.96 & 1.15 & 2.76 & 1.03 & 2.86 & 1.09 & & & \\
\hline 2. Worth doing & & & & & & & $*$ & & \\
\hline Mongolian & 4.67 & 0.68 & 4.65 & 0.83 & 4.66 & 0.76 & & & \\
\hline Japanese & 4.40 & 0.86 & 4.58 & 0.61 & 4.49 & 0.74 & & & \\
\hline 3. Many paid vacations & & & & & & & $*$ & & \\
\hline Mongolian & 2.96 & 1.36 & 2.78 & 1.31 & 2.87 & 1.33 & & & \\
\hline Japanese & 3.38 & 0.99 & 3.28 & 0.98 & 3.33 & 0.99 & & & \\
\hline 4. Highly appreciated & & & & & & & $*$ & $*$ & \\
\hline Mongolian & 4.43 & 0.89 & 4.62 & 0.74 & 4.53 & 0.82 & & & \\
\hline Japanese & 3.74 & 1.14 & 3.96 & 0.87 & 3.85 & 1.01 & & & \\
\hline 5. Very well paid & & & & & & & $*$ & & \\
\hline Mongolian & 4.64 & 0.72 & 4.76 & 0.59 & 4.70 & 0.66 & & & \\
\hline Japanese & 3.92 & 0.97 & 3.86 & 0.90 & 3.89 & 0.94 & & & \\
\hline 6. Less stress and fatigue & & & & & & & $*$ & & \\
\hline Mongolian & 4.33 & 0.98 & 4.39 & 0.97 & 4.36 & 0.98 & & & \\
\hline Japanese & 3.68 & 1.07 & 3.69 & 1.00 & 3.69 & 1.04 & & & \\
\hline 7. Well-regulated life & & & & & & & $*$ & $*$ & \\
\hline Mongolian & 3.76 & 1.33 & 4.06 & 1.21 & 3.91 & 1.27 & & & \\
\hline Japanese & 3.30 & 1.21 & 3.43 & 1.09 & 3.37 & 1.15 & & & \\
\hline 8. Can demonstrate one's $\mathrm{f}$ & ull abil & & & & & & $*$ & & \\
\hline Mongolian & 4.61 & 0.70 & 4.68 & 0.72 & 4.65 & 0.71 & & & \\
\hline Japanese & 4.09 & 0.98 & 4.21 & 0.78 & 4.15 & 0.88 & & & \\
\hline
\end{tabular}


9. Future stability

$\begin{array}{rllllll}\text { Mongolian } & 4.62 & 0.79 & 4.82 & 0.57 & 4.72 & 0.68 \\ \text { Japanese } & 3.70 & 1.14 & 3.99 & 0.86 & 3.85 & 1.00\end{array}$

10. Not far from the place where now living

$\begin{array}{rllllll}\text { Mongolian } & 3.58 & 1.26 & 3.61 & 1.32 & 3.60 & 1.29 \\ \text { Japanese } & 2.62 & 1.36 & 3.15 & 1.36 & 2.89 & 1.36\end{array}$

$\dagger C=$ Country, $G=$ Gender ${ }^{*}$ Significant difference at $p<.05$ or $p<.01$.

With regard to "importance of foreign language", the main effect of gender, and the interaction were significant $[\mathrm{F}(1,720)=17.15$, $\mathrm{p}=.001 ; \mathrm{F}(1,720)=3.99, \mathrm{p}=.046$, respectively]. A simple main effect test showed that only women had countries differences $[\mathrm{F}$ $(1,720)=6.33, p=.012]$. Gender differences was found only in Mongolia $[\mathrm{F}(1,720)=17$. 992, $\mathrm{p}=.000]$. These results suggest that, compared to men, women in both countries give importance to foreign language abilities, and especially Mongolian women had a marked tendency.

With regard to "influenced by economic trends", the main effects of both countries, and gender, the interaction were significant $[\mathrm{F}(1$, $722)=20.99, \mathrm{p}=.000 ; \mathrm{F}(1,722)=14.09, \mathrm{p}=$ $.000 ; \mathrm{F}(1,722)=5.21, \mathrm{p}=.023$, respectively]. A simple main effect test showed that men only had country difference $[\mathrm{F}(1,722)=18.95, \mathrm{p}=$ $.000]$. Mongolian had gender difference [F (1, $722)=17.46, p=.000]$. That is, the difference between Japanese and Mongolian men was remarkable, and the result suggests that Mongolian women should be more affected by the economic situation.

\section{Motivation for entering university}

Table 4 summarizes the results of examining Mongolian and Japanese university students' motivations to go to university. We used a scale of motivation for entering university developed by Fuchigami [8], which is classified into five motives as "original function of the university," "family consideration and normative function," "moratorium function," "secondary function of the university," and "university's economic value function."

With regard to "original function of the university", an ANOVA showed a significant main effect of the country, that of gender, and significant interaction between the country and gender $[F(1,723)=34.04, p=.000 ; F(1,723)$ $=11.80, \mathrm{p}=.001 ; \mathrm{F}(1,723)=12.73, \mathrm{p}=.000$, respectively]. A simple main effect test showed that only men had country difference $[\mathrm{F}(1,723)$ $=35.50, \mathrm{p}=.000]$. Gender difference was found only in Japan $[F(1,723)=25.79, p=.000]$. These results indicate that the desire for studying at university was higher among Mongolias than among the Japanese. The responses in "family consideration and normative function" were not significant in all effects.

Regarding "moratorium function", only the main effect of country was significant [F (1, $723)=81.40, p=.000]$. Compared to Mongolians, Japanese university students showed higher moratorium function. They may not want to go to society yet; they want to spend time at university. 
Table 3. MEAN Ratings of Goals and Experience (Question 2) For Mongolian and Japanese Students

\begin{tabular}{|c|c|c|c|c|c|c|c|c|c|}
\hline \multirow{2}{*}{ Goals and Experience } & \multicolumn{2}{|c|}{ Men } & \multicolumn{2}{|c|}{ Women } & \multicolumn{2}{|c|}{ Total } & \multicolumn{3}{|c|}{ ANOVA $\dagger$} \\
\hline & M & SD & M & SD & M & SD & $\mathrm{C}$ & G & $\mathrm{C} \times \mathrm{G}$ \\
\hline \multicolumn{7}{|c|}{ 1. Going on to graduate school } & $*$ & & * \\
\hline Mongolian & 4.19 & 1.16 & 4.26 & 1.20 & 4.23 & 1.18 & & & \\
\hline Japanese & 2.62 & 1.50 & 2.29 & 1.21 & 2.46 & 1.36 & & & \\
\hline \multicolumn{7}{|c|}{ 2. Getting information about finding employment for oneself } & & & * \\
\hline Mongolian & 4.05 & 1.08 & 4.36 & 0.93 & 4.21 & 1.01 & & & \\
\hline Japanese & 4.30 & 0.66 & 4.16 & 0.79 & 4.23 & 0.72 & & & \\
\hline 3. Aptitude for specialty & & & & & & & * & & \\
\hline Mongolian & 4.14 & 1.10 & 4.23 & 0.95 & 4.19 & 1.02 & & & \\
\hline Japanese & 2.91 & 1.17 & 3.04 & 0.97 & 2.98 & 1.07 & & & \\
\hline \multicolumn{7}{|c|}{ 4. Advantage of specialty for finding employment } & * & & \\
\hline Mongolian & 4.41 & 0.77 & 4.46 & 0.89 & 4.44 & 0.83 & & & \\
\hline Japanese & 3.05 & 1.14 & 2.81 & 1.12 & 2.93 & 1.13 & & & \\
\hline \multicolumn{7}{|c|}{ 5. Importance of information processing for finding employment } & * & & \\
\hline Mongolian & 4.43 & 0.94 & 4.74 & 0.68 & 4.59 & 0.81 & & & \\
\hline Japanese & 4.27 & 3.30 & 4.12 & 0.87 & 4.20 & 2.08 & & & \\
\hline \multicolumn{7}{|c|}{ 6. Proficiency in information processing } & * & $*$ & \\
\hline Mongolian & 4.07 & 1.14 & 3.99 & 1.06 & 4.03 & 1.10 & & & \\
\hline Japanese & 2.83 & 1.04 & 2.48 & 0.95 & 2.66 & 1.00 & & & \\
\hline \multicolumn{7}{|c|}{ 7. Importance of foreign language } & & $*$ & * \\
\hline Mongolian & 3.92 & 1.28 & 4.40 & 0.94 & 4.16 & 1.11 & & & \\
\hline Japanese & 3.99 & 1.08 & 4.16 & 0.83 & 4.08 & 0.95 & & & \\
\hline \multicolumn{7}{|c|}{ 8. Proficiency in foreign language } & * & & \\
\hline Mongolian & 3.15 & 1.20 & 3.17 & 1.21 & 3.16 & 1.20 & & & \\
\hline Japanese & 2.25 & 1.11 & 2.01 & 1.01 & 2.13 & 1.06 & & & \\
\hline \multicolumn{7}{|l|}{ 9. Parental influences } & * & $*$ & \\
\hline Mongolian & 3.09 & 1.47 & 3.46 & 1.42 & 3.28 & 1.45 & & & \\
\hline Japanese & 2.73 & 1.31 & 2.78 & 1.31 & 2.76 & 1.31 & & & \\
\hline \multicolumn{7}{|l|}{ 10. Friends' influences } & * & & \\
\hline Mongolian & 3.26 & 1.41 & 3.13 & 1.44 & 3.20 & 1.43 & & & \\
\hline Japanese & 2.80 & 1.25 & 2.84 & 1.14 & 2.82 & 1.20 & & & \\
\hline \multicolumn{7}{|l|}{ 11. Teachers' influences } & * & & \\
\hline Mongolian & 3.06 & 1.39 & 3.17 & 1.45 & 3.12 & 1.42 & & & \\
\hline Japanese & 2.78 & 1.19 & 2.92 & 1.11 & 2.85 & 1.15 & & & \\
\hline
\end{tabular}

\begin{tabular}{|c|c|c|c|c|c|c|c|c|c|}
\hline \multirow{2}{*}{ Goals and Experience } & \multicolumn{2}{|c|}{ Men } & \multicolumn{2}{|c|}{ Women } & \multicolumn{2}{|c|}{ Total } & \multicolumn{3}{|c|}{ ANOVA $\dagger$} \\
\hline & $\mathrm{M}$ & $\mathrm{SD}$ & $\mathrm{M}$ & $\mathrm{SD}$ & $\mathrm{M}$ & $\mathrm{SD}$ & $\mathrm{C}$ & $\mathrm{G}$ & $\mathrm{C} \times \mathrm{G}$ \\
\hline 12. Economic trends & & & & & & & $*$ & $*$ & * \\
\hline Mongolian & 3.03 & 1.41 & 3.61 & 1.36 & 3.32 & 1.39 & & & \\
\hline Japanese & 3.69 & 1.20 & 3.83 & 1.03 & 3.76 & 1.12 & & & \\
\hline 13. Going to another school & & & & & & & * & * & \\
\hline Mongolian & 3.95 & 1.36 & 4.20 & 1.25 & 4.08 & 1.31 & & & \\
\hline Japanese & 1.83 & 1.03 & 2.05 & 1.05 & 1.94 & 1.04 & & & \\
\hline
\end{tabular}

$\dagger \mathrm{C}=$ Country, $\mathrm{G}=$ Gender ${ }^{*}$ Significant difference at $\mathrm{p}<.05$ or $\mathrm{p}<.01$. 
Table 4. Mean Ratings of Study in University Motives (Question 1) For Mongolian and Japanese Students

\begin{tabular}{|c|c|c|c|c|c|c|c|c|c|}
\hline \multirow{2}{*}{ Motives of Study in University } & \multicolumn{2}{|c|}{ Men } & \multicolumn{2}{|c|}{ Women } & \multicolumn{2}{|c|}{ Total } & \multicolumn{3}{|c|}{ ANOVA $\uparrow$} \\
\hline & $\mathrm{M}$ & SD & $\mathrm{M}$ & SD & $\mathrm{M}$ & $\mathrm{SD}$ & $\mathrm{C}$ & $\mathrm{G}$ & $\mathrm{C} \times \mathrm{G}$ \\
\hline 1. Original function of university & & & & & & & $*$ & $*$ & $*$ \\
\hline Mongolian & 4.10 & 0.72 & 4.09 & 0.86 & 4.10 & 0.79 & & & \\
\hline Japanese & 3.56 & 0.76 & 3.96 & 0.61 & 3.76 & 0.69 & & & \\
\hline
\end{tabular}

2. Family considerations and normative functions

$\begin{array}{cllllll}\text { Mongolian } & 2.45 & 1.54 & 2.37 & 1.51 & 2.41 & 1.53 \\ \text { Japanese } & 2.34 & 1.38 & 2.53 & 1.32 & 2.44 & 1.35\end{array}$

3. Moratorium function

$\begin{array}{lllllll}\text { function } & & & & & & \\ \text { Mongolian } & 1.88 & 0.99 & 1.77 & 1.06 & 1.83 & 1.03 \\ \text { Japanese } & 2.61 & 1.20 & 2.57 & 1.14 & 2.59 & 1.17 \\ \text { function of university } & & & & & & \\ \text { Mongolian } & 2.67 & 1.09 & 2.47 & 1.05 & 2.57 & 1.07 \\ \text { Japanese } & 3.30 & 0.84 & 3.52 & 0.80 & 3.41 & 0.82\end{array}$

5. Economic value function of university

$\begin{array}{cllllll}\text { Mongolian } & 3.74 & 0.84 & 3.71 & 0.99 & 3.73 & 0.92 \\ \text { Japanese } & 3.31 & 0.90 & 3.35 & 0.86 & 3.33 & 0.88\end{array}$

$\dagger \mathrm{C}=$ Country, $\mathrm{G}=$ Gender $*$ Significant difference at $\mathrm{p}<.05$ or $\mathrm{p}<.01$.

Regarding "secondary function of the university", the main effect of country, and the interaction were significant $[\mathrm{F}(1,723)=$ $132.09, \mathrm{p}=.000 ; \mathrm{F}(1,723)=8.66, \mathrm{p}=.003$, respectively]. There were significant differences between countries in both men and women's results of the simple main effect $[\mathrm{F}(1$, $723)=29.36, \mathrm{p}=.000 ; \mathrm{F}(1,723)=138.02, \mathrm{p}=$ $.000]$. Gender difference was found only in Japan $[\mathrm{F}(1,723)=4.89, \mathrm{p}=.027]$. Thus, the reason for meeting many people at the university was higher in Japan, and women tended to give higher importance to this aspect as compared to men.

Regarding "university's economic value function", the only main effect of country was significant $[\mathrm{F}(1,724)=31.64, \mathrm{p}=.000]$. Both countries showed very comparable values, but the average in Mongolia was slightly higher compared to Japan. There was a strong desire to find a job in a large company after graduating from the university. In developing countries like Mongolia, the social situation that places importance on an educational background society increases year by year. Going to university and expectations for the future economic situation are directly connected.

The present study was conducted to clarify the characteristics of Mongolian students' awareness regarding their career decision-making. This was also compared to those of Japanese students. Our findings revealed that although Mongolian and Japanese students have similar occupational views, there are some cultural differences. We discussed our findings as follows.

Previous studies revealed interesting psychological characteristics of Japanese students. For example, Fuchigami [8] studied "motivation to go to university" for 506 high school students in Japan. His study showed that the students who recognized that their teachers influenced them had a strong motive for the "original function of the university." The students who realized that their father influenced them tended to emphasize "economic value functions," and those influenced by their mother tended to emphasize "family consideration and normative functions" [8].

Yanai et al. [14] studied various aspects, such as career decisions and university majors' aspirations for 90,906 second-year high school students. The results showed high affirmation rates for reasons such as "advantageous for employment," "acquiring broad education," "acquire a high degree of education," "spreading human relationships." Mainly, the 
boys highly emphasized on realistic factors, such as "high degree of education" and "employment conditions". Girls emphasized the factors related to personality formation, such as "broad education," "human relations," and "discovering aptitude" [14, 15].

Yamashita et al. [10] compared university students' experience, goals, and career decisions in Japan with those in Korea. The results were similar between Japan and Korea, but slightly different from Korea's conscription system. On the other hand, Japanese students attach less importance to welfare factors, such as "less fatigue" and "paid vacation days" as they advance to the upper grades. This is because, in Japan, university students have a culture of getting a job immediately after graduation from university. Also, difficulty in hunting a job is strongly influenced by economic trends, such as business activeness on Japanese students' consciousness of making a choice occupation. Korean students may have time to think because they have a couple of years of conscription period. In both Japan and South Korea, males answered that men had specialized abilities and advantageous for employment rather than women. Koreans attach significant importance to individual performance, corporate economic value, and social evaluation when looking for a job [10]. The purpose of this study was to examine and compare Mongolians (118 men and 252 women) and Japanese (158 men and 201 women) university students' awareness related to their occupation and their motivations for entering university. Our findings obtained from the present study revealed that when Mongolians make a career decision, the most important factors were "worth doing" and "can demonstrate one's full ability," followed by "economic value and future stability," especially for women. Women tended to be more active than men after the second half of the 20th-century. Before this, we had a common notion that men had to work and feed their families. However, in the $21 \mathrm{st}$ century, this notion is changing drastically. The social situation influences substantial changes, such as gender issues and the background of digitized society. Also, focusing on women's social advancement in Mongolian culture, gender egalitarianism is deeply rooted due to the influence of Marxism-Leninism from the socialist era. Most current active leaders have been educated through Russian education system at their young age $[1,2,3]$. In terms of gender equality, women's social advance was formed earlier in Mongolia than in Japan. Besides, the digital society has increased, the volume of information has increased, and women can now live without relying on men. However, women are more concerned about economic value in a society in which wage gaps are gender-biased especially in Japan.

Regarding the item "importance of foreign language" results when looking for a job, Mongolian women show remarkably high average rate. Studying foreign languages is a way for women to get their job to live without depending on men. Also, many Mongolian companies emphasize foreign language skilled persons as a mandatory condition in recruitment. As its background, in the socialist era, Mongolia recognized only contact with socialist countries through the Soviet Union. It can be said that after Mongolia became free and democratic, the country easily connected with foreign, especially Western countries. Tourism is also an important revenue area of the country. On the other hand, Japanese students tended to answer that they understand the important of foreign languages but lack confidence in applying it in practice. Compared to other countries, we may need to consider Japanese culture, which believes that modesty is beautiful. As a Japanese proverb goes, "A wise man keeps some of his talents in reserve," and Japanese students tend not to overestimate themselves. It is necessary to study further how young people change in rapidly developing countries, such as Mongolia.

compared the youth of Mongolia, the country that went through socialism, with young people 
in Japan, a highly developed industrialized country. According to this survey, Mongolian female students demonstrate higher ambition and aspiration to be independent, which is similar to male students of Japan. While the male students of Mongolia are similar to female students of Japan in terms of aspiration. This

\section{REFERENCES}

1. Koide, T., (2006) Educational Reform after 1990 in Mongolia. Hokkaido University Collection of Scholarly and Academic Papers 98, 263-302 [in Japanese]

http://doi.org/10.14943/b.edu.98.263.

2. Koide, T., (2007) Educational Reform after 1990 in Mongolia. Hokkaido University Collection of Scholarly and Academic Papers 100, 167-219 [in Japanese]

http://doi.org/10.14943/b.edu.100.167.

3. Koide, T., (2009) Educational Reform after 1990 in Mongolia. Hokkaido University Collection of Scholarly and Academic Papers 106, 149-181 [in Japanese]

http://doi.org/10.14943/b.edu.106.149.

4. David Sneath and Christopher Kaplonski (2010) The History of Mongolia, Vol.1,2,3, Global Oriented LTD.

5. Bat-Ochir Bold (2001) Mongolian Nomadic Society - A Reconstruction of the 'Medieval' History of Mongolia, Curzon Press Richmond, Surrey.

6. Mongolian Statistical Yearbook (2019) National Statistics Office of Mongolia.

7. Yukiko Inoue-Smith, (2014) Gender Differences in Aspirations for Career and Marriage among Japanese Young Adults: Evidence from a Large National University in Japan. Journal of International Women's Studies, 2014 Vol.15-2

https://vc.bridgew.edu/jiws/vol15/iss2/ 8/

8. Fuchigami, K., (1984) A Study on the Motives and Decision Making Processes of High-school Students' Entering the Universities. The Japanese aspect needs to be studied in detail through further research. We will continue our research to bring to light psychological differences and similarities of the youth of $\mathrm{X}, \mathrm{Y}$ and $\mathrm{Z}$ generations of both the countries in a broader scope.

Journal of Educational Psychology, 1984, 32, pp. 59-63. [in Japanese] https://www.jstage.jst.go.jp/article/jjep 1953/32/1/32_59/_article/-char/ja/

9. Yamashita, T. (1991) [Human support system for occupational problems on the basis of fuzzy theory]. [Monthly Journal of the Japan Institute of Labour], 33(10), pp. 13-21. [in Japanese]

10. Yamashita, T., Youn, G., Matsumoto J., (1999) Career Decision-making in College students Career decisionmaking in college students: crosscultural comparisons for Japan and Korea. Psychological Reports, 1999, 84, pp. 1142-1157.

https://journals.sagepub.com/doi/10.24 66/pr0.1999.84.3c. p. 1143.

11. Japan Institute of Labour (1991) [A study on determinant factors of career plans of young men]. Tokyo: The Japan Institute of Labour. [in Japanese]

12. Japan Institute of Labour (1992) [College students' career plans]. Tokyo: The Japan Institute of Labour. [in Japanese]

13. Mongolian Statistical Yearbook (2011) National Statistics Office of Mongolia.

14. Yanai, H., Shimizu, T., Maekawa, S., Suzuki, N., (1989) Analysis of the Survey for Career Guidance and University Information. Research bulletin of National Center for University Entrance Examinations 1989, 18, pp. 1-71. [in Japanese]

15. Furuichi, Y., (1993) Student's Motives for entrance into University and Value Orientation. Career Guidance Study 1993. No.14, The Japanese Society for the Study of Career Education. [in 
Japanese]

https://ci.nii.ac.jp/naid/110007368631.

16. Fuchigami, K., (1986) A study of personal influences on decision making in entering universities. The Japanese Journal of Educational Psychology, 1986, 34, pp. 347-351. [in Japanese] https://www.jstage.jst.go.jp/article/jjep 1953/34/4/34_347/_article/-char/ja/

17. Gottfredson, L. S. (1981) Circumscription and compromise: a developmental theory of occupational aspirations. Journal of Counseling Psychology. Monograph, 28, pp. 545579.

https://psycnet.apa.org/record/198203363-001

18. Hesketh, B., Pryor, R., \& Gleitzman, M., (1989) Fuzzy logic: Toward measuring Gottfredson's concept of occupational social space. Journal of Counseling Psychology, 36, pp.103109. https://psycnet.apa.org/record/1989-

17590-001

19. Blanchard, C., and Lichtenberg, J., (2003) Compromise in career decision making: A test of Gottfredson's theory. Journal of Vocational Behavior 62 (2003) 250-271.

https:/www.sciencedirect.com/science /article/abs/pii/S000187910200026X

20. Examination of reasons for admission to music college and factors affecting adaptation after admission. The Japanese Journal of Educational Psychology, 2005, 53, pp. 49-61. [in Japanese]

https://www.jstage.jst.go.jp/article/jjep 1953/53/1/53_49/_article/-char/ja/

21. Jieqiong Fan, (2016) The role of thinking styles in career decisionmaking self-efficacy among university students. Thinking Skills and Creativity, Vol. 20, 2016, pp. 63-73. https://www.sciencedirect.com/science /article/abs/pii/S1871187116300098 